\title{
The Diagnosis and Treatment of Hypertrophic Cardiomyopathy
}

\author{
Christian Prinz, Martin Farr, Detlef Hering, Dieter Horstkotte, Lothar Faber
}

\section{SUMMARY}

Background: Hypertrophic cardiomyopathy (HCM) is the most common hereditary disease of the heart.

Methods: In this article, we summarize the current state of the diagnosis and treatment of HCM on the basis of a selective review of recent publications with relevance to clinical practice.

Results: Several hundred mutations in more than 27 genes, most of which encode sarcomeric structures, are associated with the HCM phenotype. Thus, HCM can be thought of as a sarcomeric disease, with myocardial fiber disarray as its histological hallmark. There are two types of $\mathrm{HCM}$, a more common, obstructive type (HOCM, 70\%) and a less common, non-obstructive type (HNCM; in all cases of HCM, testing should be performed to detect outflow obstruction at rest and/or on provocation, and to thereby determine whether HOCM or HNCM is present. The symptoms of HCM include dyspnea, angina pectoris, palpitations, dizziness, and occasionally syncope. Because sudden cardiac death is the most serious complication of HCM, particularly in young and asymptomatic patients, it follows that correct diagnosis, followed by risk stratification of patients with regard to the need for prophylactic implantation of an implantable cardiac defibrillator (ICD), can be of life-saving importance. The pharmacotherapy of symptomatic HNCM consists of the treatment of heart failure with a normal ejection fraction (HFNEF). In HOCM, the patient's symptoms and the obstructive gradient are the guide to treatment with beta-blockers or verapamil. For patients with drug-resistant disease, surgical myectomy and percutaneous septal ablation are now standard treatments.

Conclusion: A near-normal life expectancy and a highly satisfactory quality of life are now realistic treatment goals for patients with HCM.

- Cite this as:

Prinz C, Farr M, Hering D, Horstkotte D, Faber L: The diagnosis and treatment of hypertrophic cardiomyopathy. Dtsch Arztebl Int 2011; 108(13): 209-15.

DOI: 10.3238/arztebl.2011.0209

Kardiologische Klinik, Herz- und Diabeteszentrum NRW, Ruhr-Universität Bochum, Bad Oeynhausen: Dr. med. Prinz, Dr. rer. nat. Farr, Dr. med. Hering, Prof. Dr. med. Horstkotte, Prof. Dr. med. Faber he prevalence of hypertrophic cardiomyopathy (HCM) is estimated to be one case per 500-1000 population. The disease is characterized by excessive thickening of the left ventricular myocardium, occasionally also the right, without an identifiable cause such as arterial hypertension (Figure 1). There are two types of HCM: a more common, obstructive type (HOCM, 70\%) in which there is left ventricular outflow obstruction and a less common, non-obstructive type (HNCM). The extent and localization of the wall thickening is highly variable. The interventricular septum is often involved (1), which led to the alternative name, asymmetric septal hypertrophy. An American working group (2) suggested that HCM be defined genetically and not morphologically. The European Society of Cardiology Working Group on Myocardial and Pericardial Diseases recommends morphological classification (3).

\section{Etiology and pathogenesis}

The disease has an autosomal dominant pattern of inheritance with variable penetrance. Several hundred mutations on more than 27 genes have been identified to date. Beta-myosin heavy chain, cardiac myosin binding protein $\mathrm{C}$, and cardiac troponin $\mathrm{T}$ are the most commonly affected proteins, accounting for about $60 \%$ to $70 \%$ of all cases of HCM. Familial HCM accounts for $50 \%$ of cases with the remaining cases assumed to be spontaneous mutations (4).

Histologically, there is classical myocardial fiber disarray with cardiomyoctes thickened up to $100 \mu \mathrm{m}$ arranged in whirls and branched. It is suspected that the loss of contractility associated with this cellular disarray and interstitial fibrosis triggers the myocardial hypertrophy process. The mitral valve leaflets often appear enlarged relative to the cavity of the left ventricle.

\section{Pathophysiology}

Pump function (ejection fraction, EF) usually remains normal for years with HCM. However, fibrosis (Figure 2) and hypertrophy cause diastolic dysfunction and this is often already present at diagnosis (7). Depending on left ventricular morphology, it may result in dynamic obstruction with formation of an intracavitary systolic pressure gradient (Figure 3). An exercise test is mandatory because $50 \%$ of HOCM patients only exhibit this obstruction under provocation. References that indicate 


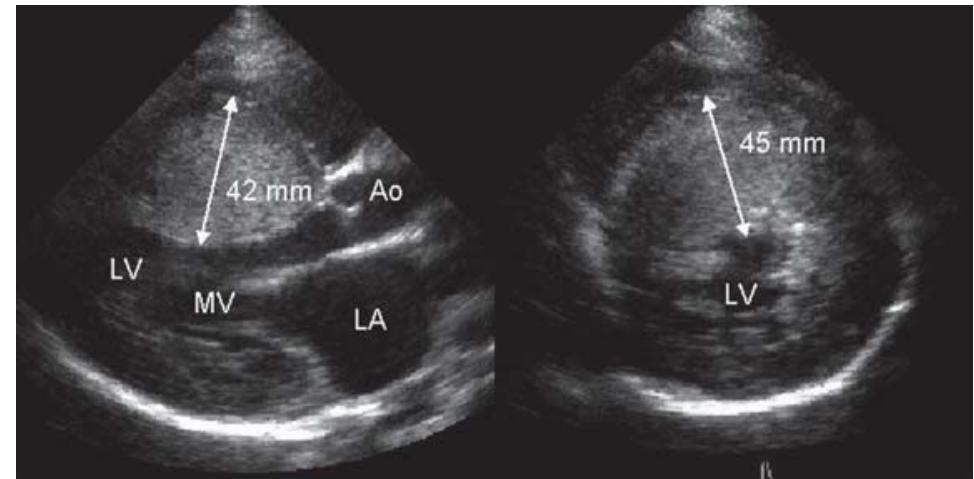

Figure 1: Patient with extreme left ventricular wall hypertrophy. Such pronounced hypertrophy is rather rarely encountered

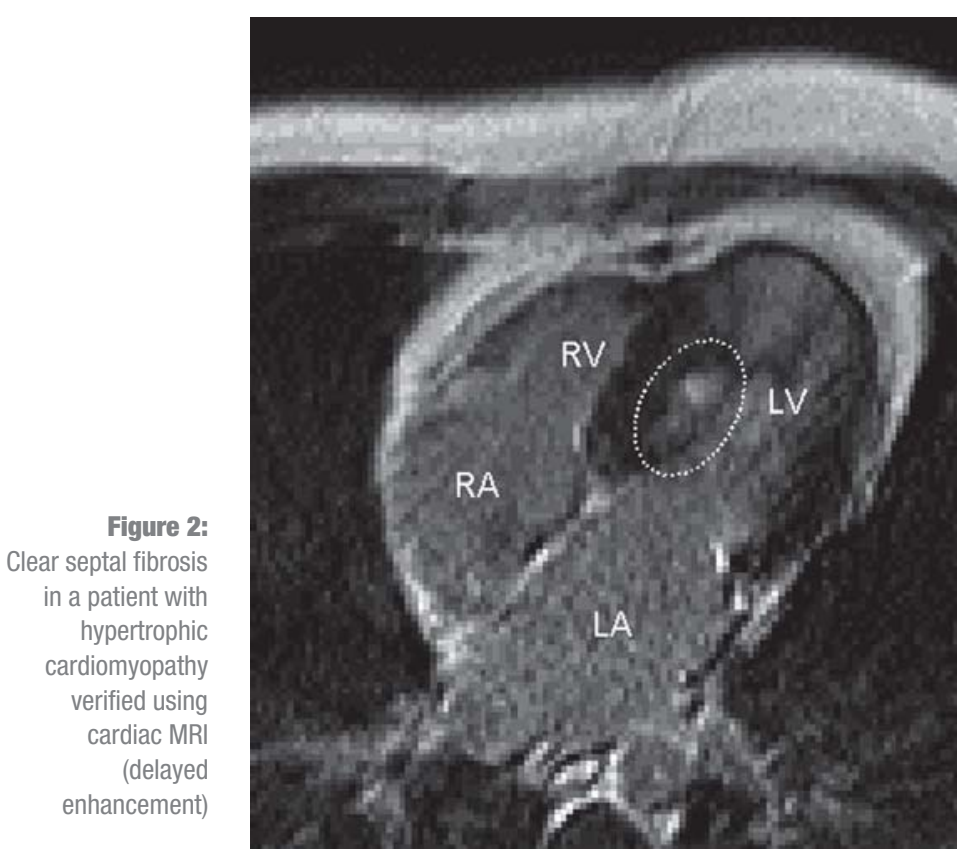

stress, dizziness, palpitations and occasionally syncope are common (11). The most dramatic symptom is sudden cardiac death, which is common in young and previously asymptomatic patients. Death occurs predominantly during or after strenuous physical exercise and is explained by malignant dysrhythmias. HCM is the most common cause of sudden death in athletes (12).

\section{Diagnosis \\ Physical findings}

HNCM is usually silent on auscultation. Due to increased atrial pressure occasionally a fourth heart sound can be heard. With HOCM a systolic murmur can usually be detected on auscultation due to dynamic obstruction and its associated mitral regurgitation. The Valsalva maneuver or short-acting preload reducers (acute nitrate therapy) may result in an increased degree of obstruction or an increase in the intensity of the auscultatory findings. Be aware of the stigmata of systemic diseases occasionally associated with HCM such as Noonan's syndrome (facial dysmorphia) or Anderson-Fabry disease (typical maculopapular skin lesions).

\section{ECG}

In $75 \%$ to $95 \%$ of $\mathrm{HCM}$ patients the ECG shows changes in the form of left ventricular hypertrophy (13). Twenty-five percent of patients exhibit a left anterior hemiblock or a left bundle branch block. The configuration of hypervoltage and giant negative $\mathrm{T}$ waves is typical for HNCM, and pseudoinfarct Q waves are typical for HOCM. Hyperacute negative $\mathrm{T}$ waves are characteristic for the apical form of HCM (14). Peripheral low voltage suggests a storage disease or cardiac amyloidosis and should initiate a myocardial biopsy $(15,16)$. A normal ECG does not exclude the presence of HCM but suggests a mild manifestation of the disease (17).

\section{Echocardiography}

There is a broad spectrum of morphological findings, ranging from isolated thickening of individual myocardial segments that deviate from the normal LV wall thickness $(<12 \mathrm{~mm})$ by only a few millimeters to diffuse and massive hypertrophy and wall thicknesses up to $60 \mathrm{~mm}$. A maximal wall thickness of $>30 \mathrm{~mm}$ is a risk marker for sudden cardiac death (Figure 1) (18). The right ventricle is only rarely involved. Particular attention must be paid to the presence of an obstruction of the left ventricular outflow tract together with SAM. The obstruction can be reliably quantified using Doppler echocardiography by determining the increased systolic flow velocities in the left ventricular outflow tract or by calculating the pressure gradients. Provocation is mandatory and can be induced pharmacologically or using the Valsalva maneuver or ergometric exercise. Postextrasystolic potentiation (Brockenbrough sign, Figure 3) is also typical. A consensus document (19) recommends dynamic stress ergometry. 
An increase in the afterload (blood pressure increase) or negative inotropic substances reduce the gradients, which explains a possible variability in the intraventricular pressure gradients. Enlargement of the left atrium, flattening of the EF slope of the anterior mitral leaflet, and a reduction or prolongation of the rapid filling phase all indicate diastolic ventricular dysfunction. Cardiac storage diseases or hypertrophy due to secondary causes must be considered as differential diagnoses.

\section{Other imaging modalities}

Maximal wall thicknesses and determination of the left ventricular muscle mass can also be determined using cardiac MRI and cardiac CT. Myocardial scar tissue can be detected using delayed-enhancement cardiac MRI (Figure 2). A recently published study indicates that there may be a relationship between the extent of fibrosis and the risk of ventricular arrhythmias (20). A relationship has been described between disrupted microcirculation and subsequent scar formation with a tendency toward arrhythmia (21).

\section{Exercise tests}

The objective capacity should be determined in patients with HCM using spiroergometry because a subjective estimate of symptoms is often misleading due to prolonged restriction and adaptation. This method also provides information about blood pressure response at rest and under load (risk stratification) (22).

\section{Rhythm diagnostics}

A 48-hour (ambulatory) Holter ECG recording to detect non-sustained ventricular tachycardia is essential for risk stratification. Invasive electrophysiological examination has become less important in recent years. We only carry out this type of recording for specific instances (for example, suspicion of concomitant WolffParkinson-White syndrome) (23).

\section{Invasive diagnostics}

Invasive diagnostics are used to exclude or verify coexistent coronary sclerosis, for imaging of the vascular supply to the septum prior to planned septal ablation, and to verify prognostically relevant myocardial bridging. Myocardial biopsies can be useful to exclude storage diseases (amyloidosis). Invasive gradient determination is rarely necessary (poor echo window). Elevated end-diastolic LV pressure is usually an expression of a lack of distensibility (Figure 4). With corresponding clinical staging (NYHA III), invasive examination should be used as part of a step-by-step diagnostic approach.

\section{Molecular genetics}

First-degree relatives should be examined for the presence of HCM. If genetic diagnostics are not possible, adolescents between 12 and 18 years of age should be examined annually, and adults over 18 years of age every five years, using echocardiography (19).

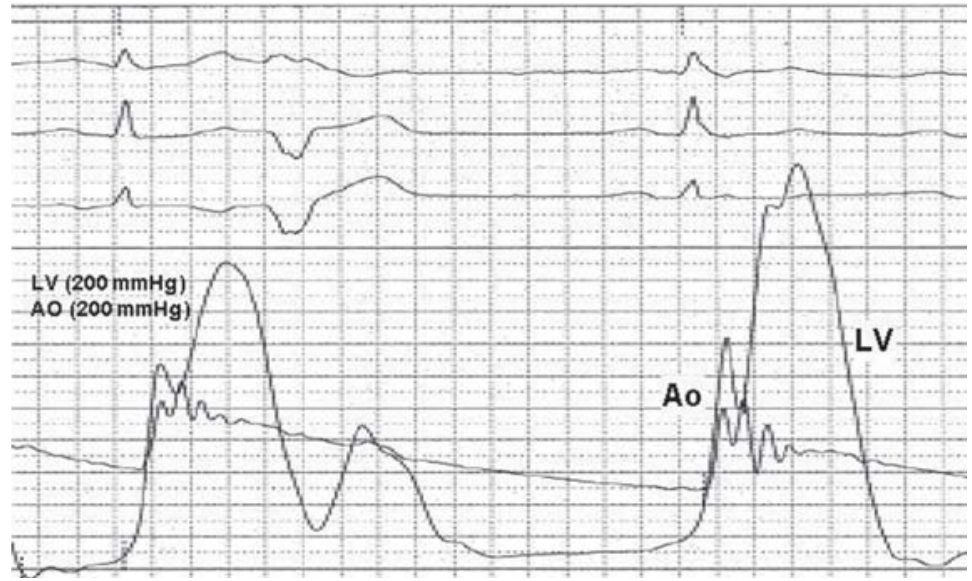

Figure 3: Documentation of an aortic and a ventricular pressure curve with evidence of postextrasystolic potentiation (Brockenbrough sign)

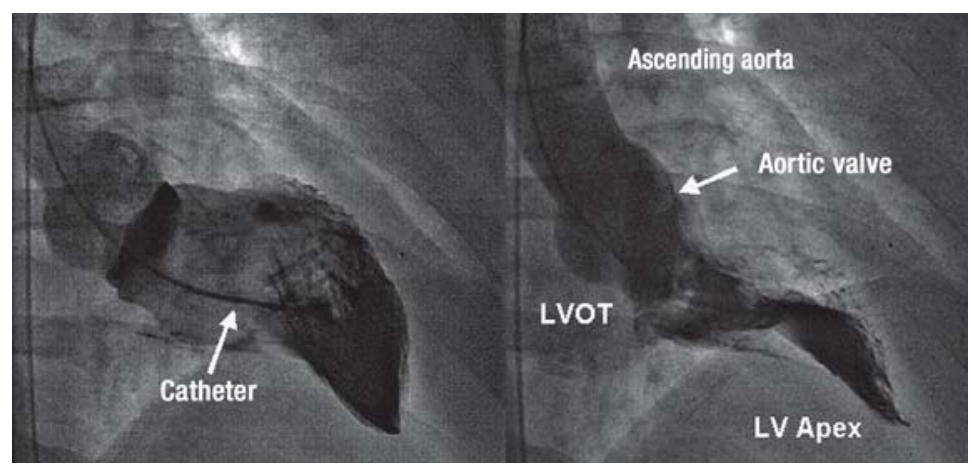

Figure 4: LV angiogram of a patient with HCM

\section{Therapeutic options \\ General measures}

Therapeutic recommendations are mostly based on observational studies or case series. Naturally, large randomized trials are not available due to the relatively low prevalence of this cardiac disease. Results for symptomatic therapy using alcohol-induced myocardial ablation are only available from medium-term studies to date. The essentials of the recommendations developed in 2003 by an international expert committee are still valid (19). It is recommended to adapt physical activity characterized by endurance in the aerobic range (abstaining from high-performance sports, athletics or competitive sports); a general prohibition on sport does not appear to be justified. Noxious substances such as nicotine or alcohol should not be ingested; the latter can aggravate outflow tract obstruction and cause arrhythmias. The earlier indication for infective endocarditis prophylaxis with HOCM has since been qualified (24).

\section{Risk stratification}

Due to the risk of sudden cardiac death, identification of high-risk HCM patients is a particular challenge with regard to the need to implant an ICD (implantable 
TABLE 1

Algorithm to identify at-risk HCM patients for implantation with an ICD 25

\begin{tabular}{l|l} 
First degree risk factors & Definition \\
$\begin{array}{l}\text { Positive family history of sudden cardiac } \\
\text { death }\end{array}$ & Cases with SCD $<45$ years \\
\hline Recurrent syncope & $\geq 2$ incidents \\
\hline LVH & $\geq 30 \mathrm{~mm}$ at any site in the LV \\
\hline $\begin{array}{l}\text { Abnormal blood pressure response } \\
\text { during exercise }\end{array}$ & $\begin{array}{l}\text { Increase }<20 \mathrm{~mm} \mathrm{Hg} \text { or fall } \\
>20 \mathrm{~mm} \mathrm{Hg} \text { after transient increase }\end{array}$ \\
\hline Non-sustained VT in Holter ECG & $\begin{array}{l}\geq 3 \text { consecutive QRS complexes with a } \\
\text { heart rate of } \geq 120 \text { bpm. }\end{array}$ \\
$\begin{array}{l}\text { Second degree risk factors } \\
\begin{array}{l}\text { Atrial fibrillations/atrial flutter } \\
\text { LA dilatation }\end{array}\end{array}$ & $\begin{array}{l}\text { Any form, provided cannot be eliminated } \\
>45 \mathrm{~mm} \text { (in m-mode ECG) } \\
\text { High LVOT gradient at rest } \\
\begin{array}{l}\text { Evidence of myocardial ischemia during } \\
\text { exercise }\end{array}\end{array}$ \\
$\begin{array}{l}\text { Early manifestation of HCM } \mathrm{mm} \text { (CW Doppler) } \\
\text { Myocardial bridging near the LAD } \\
\text { Marked fibrosis in cardiac MRI }\end{array}$ & $\begin{array}{l}<30 \text { years of age } \\
\text { in younger patients (<45 years) } \\
\text { fibrosis of } \geq 2 \text { segments in a 17-segment } \\
\text { model of the LV }\end{array}$ \\
\hline
\end{tabular}

SCD, sudden cardiac death; LVH, left ventricular hypertrophy; LA, left atrium; LV, left ventricle; LVOT, left ventricular outflow tract; VT, ventricular tachycardia; $L A D$, left anterior descending artery

cardioverter defibrillator). Five major risk factors have been identified to date (25). With a relatively low positive predictive value for the individual risk factors, combining them increases their significance considerably (e1).

- There is a positive family history of premature sudden cardiac death caused by HCM in about $25 \%$ of the affected families $(<45$ years of age) (25).

- Documented non-sustained ventricular tachycardia (NSVT) is a sensitive marker for increased risk of suffering sudden cardiac death. The absence of NSVT is also diagnostically useful because of the high negative predictive value (e2).

- Syncope at rest or during exercise is an important risk marker for all age groups.

- An abnormal blood pressure response during exercise is defined as an increase in the systolic blood pressure of less than $20 \mathrm{~mm} \mathrm{Hg}$ from the baseline value. A progressive fall in blood pressure during exercise or a fall in the systolic value by $20 \mathrm{~mm} \mathrm{Hg}$ after an initial increase (e3), particularly in younger patients ( $<40$ years of age) is also assessed as being associated with risk (22).

- Extreme left ventricular hypertrophy with wall thicknesses $>30 \mathrm{~mm}$ (Figure 1) is also associated with risk. The highest rate of cases of sudden cardiac death in adolescents was linked with pronounced hypertrophy (e4).

Additional risk factors only studied in smaller patient collectives are listed in Table 1. More recent studies consider marked fibrosis (cardiac MRI) to be an additional risk factor (20). Table 1 shows the algorithm used by us to identify at-risk HCM patients. Patients without any of the listed risk markers have a high probability of a good prognosis. We consider two firstdegree risk markers to be an indication for primary prophylactic ICD implantation. An individual decision must be made for patients with one first-degree risk marker. Second-degree risk factors may provide additional support for decisions. A previously survived cardiac arrest or documentation of sustained ventricular tachycardia are clear indications for ICD implantation (e5).

\section{Asymptomatic patients}

It is unclear whether pharmacotherapy is indicated for asymptomatic patients due to an absence of data. We advise initiating pharmacotherapy using beta blockers for pathophysiological considerations. A risk evaluation should be done in precisely this group of patients. Strict control of any coexistent arterial hypertension (reduction of the myocardial growth stimulus) is of particular importance (e6).

\section{Symptomatic patients with HNCM}

Due to the ubiquitous presence of diastolic dysfunction, heart rate should be strictly controlled using beta blockers or verapamil-type calcium antagonists. Diuretics and ACE inhibitors/AT receptor antagonists may be used with signs of congestion or concomitant hypertension, ensuring tight monitoring because in individual cases induction of an outflow tract obstruction was also detected in patients initially recorded as having HNCM. Animal experimental studies postulate a reversal of fibrosis with favorable long-term effects with treatment using AT receptor antagonists (e7), statins (e8), or spironolactone (e8). Atrial fibrillations with loss of active ventricular filling in HNCM are often associated with a considerable drop in output and a risk of cardiac embolic events. Anticoagulants should be promptly administered. Amiodarone can prevent recurrence of atrial fibrillations without reducing the risk of sudden cardiac death (e10). There are also different methods available for ablation of atrial fibrillation but as these patients' substrates are diseased, these have less favorable outcomes.

\section{Symptomatic patients with HOCM}

Agents to reduce pre- or afterload (such as nitrate, ACE inhibitors, nifedipine-type calcium antagonists) are contraindicated with HOCM due to possible aggravation of the outflow tract obstruction. This often impedes therapy of coexistent arterial hypertension. Positive inotropic drugs such as digitalis preparations must also be not be used. We prefer the use of beta blockers which improve LV filling by prolonging the diastolic filling period and reduce obstruction of the outflow tract due to a negative inotropic effect (e11). If beta blockers are not tolerated or are not sufficiently effective, a switch to verapamil-type calcium antagonists, which also improve ventricular filling and reduce obstruction, can be effective (1). If coexistent arterial 
hypertension must be treated simultaneously, exacerbation of the obstruction can usually be avoided by using diuretics and/or central alpha blockers (e6).

Septal myectomy using the Morrow procedure has been defined as the therapy standard from many years for patients with HOCM who cannot be adequately treated using pharmacotherapy. The procedure involves removal of a part of the hypertrophied basal septum or thinning of the remaining septum to 5 to $8 \mathrm{~mm}$. A reduction or elimination of the gradient was achieved in more than $90 \%$ of patients. The procedure is clearly indicated with symptoms corresponding to NYHA class III and a gradient $>50 \mathrm{~mm} \mathrm{Hg}$ (rest or provocation). Perioperative mortality in experienced centers is approximately $1 \%$ to $2 \%$ (e12) and the rate of complete AV blocks postoperatively is $2 \%$ to $5 \%$. An improvement in the prognosis is postulated (e13) but cannot be verified due to the lack of randomized comparisons with conservatively treated patients. Figure 6 shows the echocardiogram of a patient before and after myectomy.

Attempts have also been made to reduce the obstruction of the left ventricular outflow tract by using pacemaker stimulation. After a euphoric response to this technique in the 1990s (e14), more recent studies have demonstrated a significant placebo effect. The gradient could only be reduced by $25 \%$ to $50 \%$ on average (e15). This procedure has since been considered only for niche indications.

The range of therapeutic options for symptomatic HOCM patients was expanded with the introduction of percutaneous septal ablation (known as PTSMA, TASH, ASA or ESA). The procedure involves injecting 1 to $3 \mathrm{~mL}$ of $96 \%$ ethanol into one of the septal branches supplying the hypertrophied myocardium (e16), causing acute regional contractile dysfunction and leading to a thinning over the long term. This iatrogenic chemical necrosis results in a clear reduction or elimination of the obstruction in $90 \%$ of cases (Figures 5 and 6$)$. Mortality associated with the procedure is similar to that for myectomy $(1 \%$ to $2 \%)$ in experienced centers. High-grade AV blocks that required implantation of a pacemaker initially occurred in up to $30 \%$ of patients (e17) but this has since been reduced in established centers to significantly lower values of up to $5 \%$. In contrast to myectomy, a delayed reduction in the gradients is often observed in conjunction with a low but significant regression in wall thickness, also in other LV regions (e18). Figure 6 shows the result of a septal ablation procedure, which is similar to that achieved with myectomy, four months after the intervention. From 1994 to 1999 more than 3000 septal ablations were carried out, more than the total number of surgical myectomies performed since 1960 (e19, e20, e21). The question of whether the procedure has a favorable effect not only on symptoms but also on the prognosis remains open. Fears that the septal necrosis associated with this procedure may create a new prognostically unfavorable arrhythmogenic substrate have not been confirmed through longitudinal observations

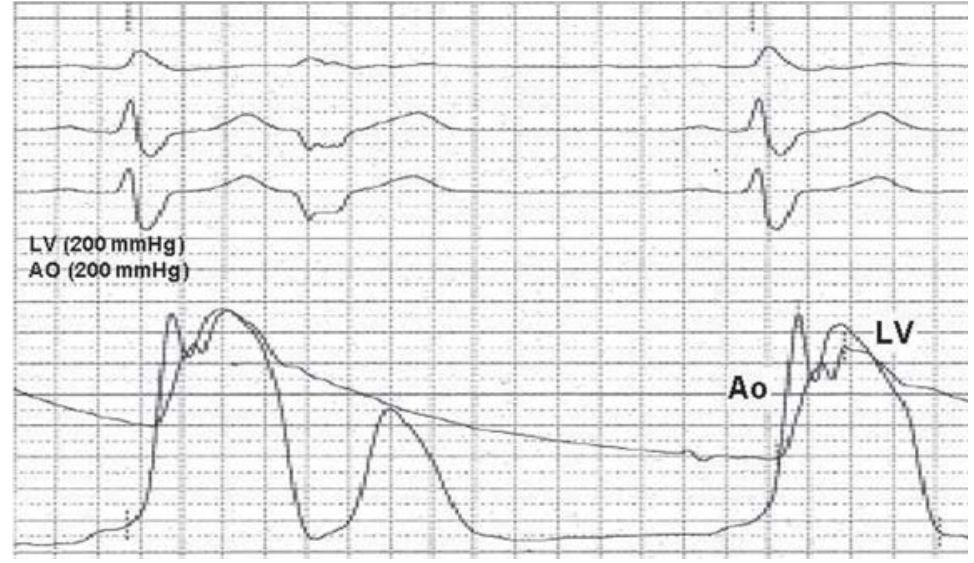

Figure 5: Documentation of an aortic and a ventricular pressure curve after performing alcohol ablation with no evidence of a significant pressure gradient following the intervention

(e22). Survival curves after myectomy and septal ablation-although this is a non-randomized comparison - appear congruent. After myectomy or septal ablation we recommend continuing pharmacotherapy (beta blockers, calcium antagonists) to prevent progression of the underlying disease.

\section{Summary}

Due to its relative rarity and the complexity of its clinical symptoms, patients with HCM require continuous monitoring in, or in collaboration with, specialized centers. Every patient, even asymptomatic patients, should undergo adequate risk stratification in terms of the risk of sudden cardiac death, with subsequent ICD implantation if required. Symptomatic treatment of patients with HNCM corresponds to specific treatment of heart failure. For symptomatic HOCM septal ablation and septal myectomy are now comparable procedures. The choice of method depends on the individual findings. In addition to optimizing risk stratification, by also integrating additional imaging procedures (MRI, CT) for example, longitudinal observation of patients who have received different treatments remains a priority.

\section{Conflict of interest statement}

The authors declare that no conflict of interest exists.

Manuscript received on 20 November 2009, revised version accepted on 11 March 2010.

Translated from the original German by language \& letters.

\section{REFERENCES}

1. Wigle ED: Novel insights into the clinical manifestations and treatment of hypertrophic cardiomyopathy. Curr Opin Cardiol 1995; 3: 299-305.

2. Maron BJ, Towbin JA, Thiene G, et al.: American Heart Association; Council on Clinical Cardiology, Heart Failure and Transplantation Committee; Quality of Care and Outcomes Research and Functional Genomics and Translational Biology Interdisciplinary Working Groups, Council on Epidemiology and Prevention. Circulation 2006; 113: 1807-16. 

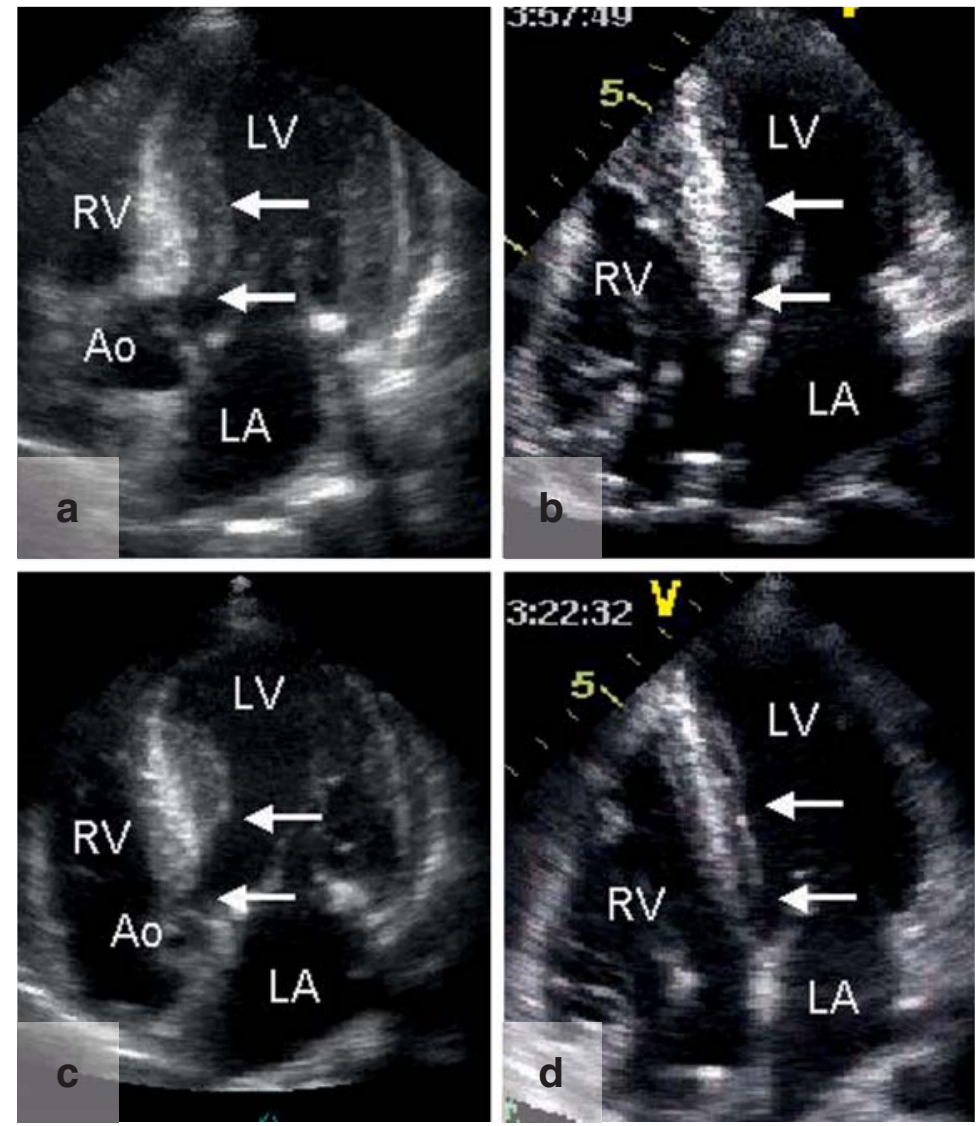

Figure 6: Echocardiogram of a patient (a) before and (c) after septal myectomy. Echocardiogram (b) before and (d) after septal alcohol ablation

3. Elliott P, Andersson B, Arbustini E, et al.: Classification of the cardiomyopathies: a position statement from the European Society of Cardiology Working Group on Myocardial and Pericardial Diseases. Eur Heart J 2008; 29: 270-6.

4. Bos JM, Towbin JA, Ackerman MJ: Diagnostic, prognostic, and theapeutic implications of genetic testing for hypertrophic cardiomyopathy. J Am Coll Cardiol 2009; 54: 201-11.

5. Maron BJ, Roberts WC: Quantitative analysis of cardiac muscle cell disorganization in the ventricular septum of patients with hypertrophic cardiomyopathy. Circulation 1979; 59: 689-706.

6. Maron BJ, Nishimura RA, Danielson GK: Pitfalls in clinical recognition and a novel operative approach for hypertrophic cardiomyopathy with severe outflow obstruction due to anomalous papillary muscle. Circulation 1998; 98: 2505-8.

7. European Society of Cardiology; Heart Failure Association of the ESC (HFA); European Society of Intensive Care Medicine (ESICM), Dickstein K, Cohen-Solal A, Filippatos G, et al.. ESC guidelines for the diagnosis and treatment of acute and chronic heart failure 2008: the Task Force for the diagnosis and treatment of acute and chronic heart failure 2008 of the European Society of Cardiology. Developed in collaboration with the Heart Failure Association of the ESC (HFA) and endorsed by the European Society of Intensive Care Medicine (ESICM). Eur Heart J 2008; 29: 2388-442.

8. Maron MS, Olivotto I, Zenovich AG, et al.: Hypertrophic cardiomyopathy is predominantly a disease of left ventricular outflow tract obstruction. Circulation 2006; 114: 2232-9.

9. Braunwald E, Wigle ED: Idiopathic hypertrophic subaortic stenosis. Chest 1973; 64: 222-4.

10. Maron MS, Olivotto I, Betocchi S, et al.: Effect of left ventricular outflow tract obstruction on clinical outcome in hypertrophic cardiomyopathy. N Engl J Med 2003; 348: 295-303.

\section{KEY MESSAGES}

- Hypertrophic cardiomyopathy ( $\mathrm{HCM})$ is the most common hereditary disease of the heart.

- The more common obstructive form ( $\mathrm{HOCM}, 70 \%)$ of hypertrophic cardiomyopathy can be differentiated from the less common non-obstructive form (HNCM, 30\%).

- In addition to the classic symptoms of heart failure such as dyspnea, there is an increased risk of sudden cardiac death, particularly in younger patients.

- Appropriate risk stratification in terms of the risk of sudden cardiac death is essential, particularly when determining if implantation of an ICD is indicated.

- In addition to pharmacotherapy for HCM, septal myectomy and septal alcohol ablation are comparable procedures that are now available to treat $\mathrm{HOCM}$.
11. Braunwald E, Lambrew CT, Rockoff SD, Ross J Jr, Morrow AG: Idiopathic hypertrophic subaortic stenosis. A description of the disease based upon an analysis of 64 patients. Circulation 1964; 30: 3-119.

12. Dilsizian V, Bonow RO, Epstein SE, Fananapazir L: Myocardial ischemia detected by thallium scintigraphy is frequently related to cardiac arrest and syncope in young patients with hypertrophic cardiomyopathy. J Am Coll Cardiol 1993; 22: 805-7.

13. Maron BJ: The electrocardiogram as diagnostic tool for hypertrophic cardiomyopathy: Revisited [editorial]. Ann Noninvas Electrocardiol 2001; 6: 277-9.

14. Yamaguchi $\mathrm{H}$, Ischimura T, Nishiyama S, et al.: Hypertrophic nonobstructive cardiomyopathy with giant negative T waves (apical hypertrophy): ventriculographic and echocardiographic features in 30 patients. Am J Cardiol 1979; 44: 401-12.

15. Bacharova L, Estes EH: Electrocardiographic diagnosis of left ventricular hypertrophy: depolarization changes. J Electrocardiol 2009; 42: 228-32.

16. Sedaghat D, Zakir RM, Choe J, Klapholz M, Saric M: Cardiac amyloidosis in a patient with multiple myeloma: a case report and review of literature. J Clin Ultrasound 2009; 37: 179-84.

17. McLeod CJ, Ackerman MJ, Nishimura RA, Tajik AJ, Gersh BJ, Ommen SR: Outcome of patients with hypertrophic cardiomyopathy and a normal electrocardiogram. J Am Coll Cardiol 2009; 54: 229-33.

18. Abbasi AS, McAlpin RN, Eber LM, Pearce ML: Echocardiographic diagnosis of idiopathic hypertrophic cardiomyopathy without outflow obstruction. Circulation 1972; 46: 897-904.

19. Maron BJ, McKenna WJ, Danielson GK, et al.: American College of Cardiology Foundation Task Force on Clinical Expert Consensus 
Documents; European Society of Cardiology Committee for Practice Guidelines. Eur Heart J 2003; 24: 1965-91.

20. Adabag AS, Maron BJ, Appelbaum E, et al.: Occurrence and frequency of arrhythmias in hypertrophic cardiomyopathy in relation to delayed enhancement on cardiovascular magnetic resonance. J Am Coll 2008; 51: 1369-74.

21. Kwon DH, Smedira NG, Rodriguez ER, et al.: Cardiac magnetic resonance detection of myocardial scarring in hypertrophic cardiomyopathy. J Am Coll Cardiol 2009; 54: 242-9.

22. Olivotto I, Maron BJ, Montereggi A, Mazzuoli F, Dolara A, Cecchi F: Prognostic value of systemic blood pressure response during exercise in a community-based patient population with hypertrophic cardiomyopathy. J Am Coll Cardiol 1999; 33: 2044-51.

23. Behr ER, Elliott $P$, McKenna WJ: Role of invasive EP testing in the evaluation and management of hypertrophic cardiomyopathy. Card Electrophysiol Rev 2002; 6: 482-6.

24. The Task force on the Prevention, Diagnosis, and Treatment of infective Endocarditis of the European Society of Cardiology (ESC). Endorsed by the European Society of Clinical Microbiology and Infectious Diseases (ESCMID) and by the International Society of Chemotherapy (ISC) for Infection and Cancer. Habib G, Hoen B, Tornos $P$, et al.: Guidelines on the prevention, diagnosis, and treatment of infective endocarditis (new version 2009). Eur Heart J 2009; 30: 2369-413.

25. Elliott PM, Poloniecki J, Dickie S, et al.: Sudden death in hypertrophic cardiomyopathy: identification of high risk patients. J Am Coll Cardiol 2000; 36: 2212-8.

\section{Corresponding author}

Dr. med. Christian Prinz

Kardiologie, Herz- und Diabeteszentrum Bad Oeynhausen

Ruhr-Universität Bochum

Georgstr. 11

32545 Bad 0eynhausen

akleemeyer@hdz-nrw.de

For eReferences please refer to:

www.aerzteblatt-international.de/ref1311 


\title{
The Diagnosis and Treatment of Hypertrophic Cardiomyopathy
}

\author{
Christian Prinz, Martin Farr, Detlef Hering, Dieter Horstkotte, Lothar Faber
}

\section{eReferences}

e1. McKenna WJ, Behr ER: Hypertrophic cardiomyopathy: management, risk stratification, and prevention of sudden death. Heart 2002; 87: 169-76.

e2. McKenna WJ, Franklin RC, Nihoyannopoulos P, Robinson KC, Deanfield JE: Arrhythmia and prognosis in infants, children and adolescents with hypertrophic cardiomyopathy. J Am Coll Cardio 1988; 11: 147-53.

e3. Frenneaux MP, Counihan PJ, Caforio AL, Chikamori T, McKenna WJ: Abnormal blood pressure response during exercise in hypertrophic cardiomyopathy. Circulation 1990; 82: 1995-2002.

e4. Spirito P, Bellone P, Harris KM, Bernabo P, Bruzzi P, Maron BJ: Magnitude of left ventricular hypertrophy and risk of sudden death in hypertrophic cardiomyopathy. N Engl J Med 2000; 342 : 1778-85.

e5. Maron BJ, Shen WK, Link MS, et al.: Efficacy of implantable cardioverter-defibrillators for the prevention of sudden death in patients with hypertrophic cardiomyopathy. N Engl J Med 2000; 342: 365-73.

e6. Musat D, Sherrid MV: Pathophysiology of hypertrophic cardiomyopathy determines its medical treatment. Anadolu Kardiyol Derg 2006; 6: 9-17.

e7. Lim DS, Lutucuta S, Bachireddy P: Angiotensin II blockade reverses myocardial fibrosis in a transgenic mouse model of human hypertrophic cardiomyopathy. Circulation 2001; 103 789-91.

e8. Patel R, Nagueh SF, Tsybouleva N: Simvastatin induces regression of cardiac hypertrophy and fibrosis and improves cardiac function in a transgenic rabbit model of human hypertrophic cardiomyopathy. Circulation 2001; 104: 317-24.

e9. Patel R, Nemoto S, DeFreitas G: Spironolactone reverses myocyte diasarray and interstitial fibrosis in the cardiac troponin T transgenic mouse model of hypertrophic cardiomyopathy [abstract]. J Am Coll Cardiol 2002; 39: 156A.

e10. Maron BJ, Olivotto I, Spirito P, et al.: Edipemiology of hypertrophic cardiomyopathy-related death: revisited in a large non-referralbased patient population. Circulation 2000; 102: 858-64.

e11. Thompson D, Naqvi N, Juul S: Effects of propranolol on myocardial oxygen consumption, substrate extraction and hemodynamics in hypertrophic obstructive cardiomyopathy. $\mathrm{Br}$ Heart J 1980; 44: 488-98.

e12. McCully RB, Nishimura RA, Tajik AJ, Schaff HV, Danielson GK: Extent of clinical improvement after surgical treatment of hypertrophic obstructive cardiomyopathy. Circulation 1996; 94: 467-71. e13. Smedira NG, Lytle BW, Lever HM, et al.: Current effectiveness and risks of isolated septal myectomy for hypertrophic obstructive cardiomyopathy. Ann Thorac Surg. 2008; 85: 127-33.

e14. Park MH, Gilligan DM, Bernardo NL, Topaz 0: Symptomatic hypertrophic obstructive cardiomyopathy: the role of dual-chamber pacing. Angiology 1999; 50: 87-94.

e15. Maron BJ, Nishimura RA, McKenna WJ, Rakowski H, Josephson ME, Kieval RS: Assessment of permanent dual-chamber pacing as a treatment for drug-refractory symptomatic patients with obstructive hypertrophic cardiomyopathy. A randomized, doubleblind, crossover study (M-PATHY). Circulation 1999; 99: 2927-33.

e16. Faber L, Seggewiss H, Gleichmann U: Percutaneous transluminal septal myocardial ablation in hypertrophic obstructive cardiomyopathy: results with respect to intraprocedural myocardial contrast echocardiography. Circulation 1998; 98: 2415-21.

e17. Seggewiss H: Percutaneous transluminal septal myocardial ablation: a new treatment for hypertrophic obstructive cardiomyopathy. Eur Heart J 2000; 21: 704-7.

e18. Mazur W, Nagueh SF, Lakkis NM, et al.: Regression of left ventricular hypertrophy after nonsurgical septal reduction therapy for hypertrophic obstructive cardiomyopathy. Circulation 2001; 103: 1492-6.

e19. Spirito P, Maron BJ: Perspectives on the role of new treatment strategies in hypertrophic obstructive cardiomyopathy. J Am Coll Cardiol 1999; 33: 1071-5.

e20. Faber L, Seggewiss H, Gietzen FH, Kuhn H, Boekstogers P, Neuhaus L, Seipel L, Horstkotte D: Catheter-based septal ablation for symptomatic hypertrophic obstructive cardiomyopathy: followup results oft he TASH-registry of the German Cardiac Society. Z Kardiol 2004; 93: 23-31.

e21. Gietzen FH, Leudner CJ, Obergassel L, Strunk-Mueller C, Kuhn H: Transcoronary ablation of septal hypertrophy for hypertrophic obstructive cardiomyopathy: feasibility, clinical benefit, and short term results in elderly patients. Heart 2004; 90: 638-44.

e22. Fernandes VL, Nielsen C, Nagueh SF, et al.: Follow-up of alcohol septal ablation for symptomatic hypertrophic obstructive cardiomyopathy the Baylor and Medical University of South Carolina experience 1996 to 2007. JACC Cardiovasc Interv 2008; 1: 561-70. 